\title{
Teachers' views on inclusive education for secondary school visually impaired learners: An example from Lesotho
}

\author{
Malehlanye Ralejoe
}

Schools' Management Advisor, Bocheletsane Combined School, Ministry of Education and Training, Lesotho rmalehlanye@yahoo.com

https://orcid.org/0000-0002-6353-1795

(Received: 9 January 2019; accepted: 9 September 2019)

\section{Abstract}

In this article I consider the views of teachers and their experiences relating to their teaching of heterogeneous learners (including some who are visually impaired) in a secondary mainstream school in Lesotho. Data was collected using focus group discussions. Two groups were formed, one consisting of four regular/mainstream teachers and the other of four support teachers. Data was analysed thematically, and the results showed that, generally, teachers preferred mainstream schooling for children with visual impairment, although resource challenges prompted them to think about special schools as alternatives in extremely under-resourced schools. The Basotho culture of communalism seemed to have played a big role in teachers' obligations to take care of all children without discrimination. Furthermore, the educational success of learners with visual impairment appeared to be a motivation for the teachers. However, they reported some challenges such as the shortage of equipment and support staff, an examination-orientated curriculum, and a hostile infrastructure. It is recommended that these be addressed by the concerned parties in order to improve inclusive education for the benefit of teachers and learners (with and without visual impairment) in the school concerned.

Keywords: inclusive education, mainstream school, regular teachers, special school, support teachers, teaching strategies, visual impairment

\section{Introduction}

Although there are several definitions of inclusive education (IE), it is understood generally to entail addressing and responding to the diversity of the needs of all learners through increasing participation in learning, cultures, and communities, and also in reducing exclusion within and from education (Booth \& Ainscow, 2000), hence ensuring quality education for all learners. In 1990, the United Nations (UN) assembled in Jomtien, Thailand, and concluded that it is through Education for All (EFA) that quality education can be ensured for all people. As a means of realising the EFA goals, the Convention on the Rights of Persons with Disabilities (CRPD) was adopted by the UN in 2006. Article 5 requires that all states "take all appropriate steps to ensure that reasonable accommodation is provided," 
(CRPD, 2006, n.p.). Article 24 of the CRPD focuses mostly on people with visual impairment (VI) by recognising braille as a way of enabling the inclusion of the visually impaired in regular schools.

Although Lesotho ratified the CRPD on 2 December 2008, progress towards complying with the requirements of CRPD is still very slow. As an example, Article 4 of the Convention calls for member states to formulate local legislation in order to adapt the Convention to local settings. Six years after ratifying the CRPD, Lesotho was commendable in drafting the Disability Equity Bill 2014. This Bill is aimed at promoting and protecting the rights of people with disabilities, including the right to physical access, the provision of education and the creation of a Disability Advisory Council. Nonetheless, this Bill was tabled in parliament for the first time only on 31 August 2018. Considering recent trends of governmental instability in Lesotho, resulting in frequent elections and in changes in parliamentary composition, and the slow pace at which things have progressed, it is unlikely that the Bill will be enacted soon into law.

Lesotho's first legal framework for the education of children with disabilities was formulated in 1989. Thereafter, the Special Education Unit was established in the Ministry of Education in 1991. Other important legal tools that followed include the Education Act of 2010, the Child Protection and Welfare Act of 2011, and the Education Sector Strategic Plan 20052015. Nonetheless, it is worth highlighting that these legal tools do not address specific needs based on different types of disabilities. Rather, they adopt a one-size-fits-all approach. This could be problematic because people with disabilities are a heterogeneous group with differing abilities and needs.

About eight years ago, Lesotho introduced a new education system called the "grade system." The grade system allows for three years of Early Childhood Care and Development (ECCD) for learners aged 3-5, seven years of primary education (Grades 1-7) for those aged 6-12, and four years of secondary education (Grades 8-11) for those between the ages of 13-16; this is followed by higher education. Only primary education is free although the government of Lesotho provides financial assistance to extremely needy children in secondary school. Across the country, children with VI were catered for in two church-owned special schools (a primary school and a secondary one), which offered education exclusively to children with VI. Presently, these schools have been transformed into inclusive schools and offer education to all types of children. The inclusive secondary school that is the subject of this study operates more on the premise of full inclusion, whereby learners with VI attend all classes with others full-time. They have a resource centre in the school for both learners with VI and their teachers.

\section{Problem statement and literature review}

In this article I investigate the views of secondary school teachers about the inclusion of visually impaired learners in their school. For this study, children were considered to have VI when their vision was such that they relied on audio tapes or the braille system for reading 
and writing. In fact, the degree of visual loss inevitably determines the type of support the child will need and the nature of educational adaptations required to enable the child to access education. Drawing on the International Classification of Diseases (ICD)-10 (2016), such children, on the one hand, would have a usable visual acuity worse than either 20/40 or 20/60. On the other, a child is considered to be blind when he/she has completely lost the ability to see. ICD-10 provides ten categories of visual function:

- Category 0: mild to no VI;

- Category 1: moderate VI;

- Category 2: severe VI;

- Categories 3, 4, 5, 6, and 7: varying degree of blindness;

- Category 8: other specified disorders of eye and adnexa classified elsewhere; and

- Category 9: unspecified VI.

Lesotho does not have a clear database showing the prevalence of disability in the country. In the early 2000s, the Ministry of Education and Training (MOET) together with the Ministry of Development Planning estimated the population of people with disabilities in Lesotho to be around 4.2\%. In its 2006 census, the Bureau of Statistics came up with an estimate of 3.7\%. Two years later, the Ministry of Health and Social Welfare estimated the number to be around 5.2\%. According to the 2006 census, the most frequent types of disability in Lesotho were VI (blindness), amputations of digits or limbs, congenital paralysis or lameness, deafness, mental illness, and mental retardation.

As argued by Belay (2005), VI in Africa has been viewed as a problem of the individual and very little has been done to improve the relationship between an individual with VI and his/her environment. In Lesotho, when a child with visible disability is born, it is traditionally perceived as being a curse to the family (Khatleli, Mariga, Phachaka, \& Stubbs, 1995). The mother is held responsible since she is regarded as having acted in ways that insulted the ancestors, and, therefore, the ancestors punished her with a disabled child. Consequently, to please what she thinks of as the spirits, and to prevent greater misfortune, the mother makes it her duty to care for the child. The coping strategies include education focusing on self-care activities, supported by the extended family since social integration and responsibility-taking are valued highly in Basotho societies. Thus, children with disabilities are never isolated from others.

Belay (2005) argues that trachoma, cataracts, and river blindness are the leading causes of VI in most African countries. According to Belay, in Africa, VI is exacerbated by poor economic, environmental, and sanitary conditions. It is also believed that exploding landmines that remain after wars and civil conflicts in Africa also contribute to VI, but Lesotho does not have a history of violent conflicts, and therefore it is unlikely that this has also contributed to cases of VI. Oculocutaneous albinism is described as an inherited condition that is usually associated with VI. As maintained by Yahalom et al. (2012), this condition is usually associated with involuntary nystagmus that causes the eyes to wobble 
involuntarily from side to side, photophobia, poor depth perception, strabismus (squint), poor visual acuity, and refractive errors.

Specific research on the inclusion of learners with VI by regular schools is scarce worldwide. Researchers on this topic (for example, Zulch (2010) in Namibia and Dakwa (2014) in Zimbabwe) have reported that the academic achievement of those with VI in mainstream schools is comparatively poorer. These studies show that mainstream school teachers often do not fully understand VI. In their 2014 Malawian study about identifying strategies to enhance the educational inclusion of visually impaired children with albinism, Lynch et al. (2014) discovered that students who could cope with eye glasses or enlarged print were taught braille because their teachers believed (wrongly) that low vision would ultimately culminate in blindness as they grew up. In South Africa, Hay, Smit, and Paulsen (2001) found that teachers lacked knowledge on issues related to IE. The teachers in their study expressed frustration and stress caused by their inadequate pre-service and in-service training in relation to IE. In Lesotho, several studies have also reported the ineffectiveness of IE as being the result of teachers' inadequate skills and knowledge of IE. For example, Ralejoe's (2016) study on regular teachers' perceptions about IE revealed that mainstream secondary school teachers had a very limited understanding of IE and they engaged in practices that contravened inclusion principles. The teachers expressed both positive and negative opinions about IE. According to Ralejoe (2016) and McLean (2008), factors that influenced teachers' perceptions of IE included the type and severity of disability, prior contact with learners with disabilities, teacher experiences with IE, administrative support, training in special education or IE, in-service training, and the presence of support staff.

Teachers are considered to be the pillars of IE and this indicates that they are crucial to making IE work. As argued by Mukhopadhyay (2013), it is important to investigate teachers' views since they could shed light on the processes and materials that could be adopted or adapted in order to improve educational access to different groups of people who were previously excluded by school systems. It is against this background that I consider this research pertinent. Thus, given the context of VI in Lesotho, its prevalence, the educational background of children with VI in the country (a shift from special schools to inclusive schools), and reports from past research about teachers' ill-preparedness to teach inclusive classes, in this study I endeavoured to investigate, from the teachers' points of view, the effectiveness of including children with VI in a mainstream secondary school in Lesotho. The study was intended to provide a platform for the teachers to express their thoughts and feelings and relate their experiences regarding the provision of education in their school, particularly in relation to teaching mixed-ability classes with some learners having VI and others not. I hoped that this would reveal key areas that need improvement in order to enable learners with VI to access the curriculum and benefit from education similar to that experienced by their peers. I also intended to use the study to inform the relevant educational authorities in Lesotho about the current situation with regard to the inclusion of visually impaired children so that they could take initiatives to provide the required support. 


\section{Methodology}

Following Sharma (2013), I chose a qualitative approach given its strengths in detailing, revealing, and describing occurrences, situations, activities, and events in their natural setting, along with the meaning they have for those who participate in them. I used purposive sampling to identify eight teachers (out of 30) in the school (four support teachers and four regular teachers), all with a minimum of two years' teaching experience. Given the gender discrepancies in the teaching staff of the school (female teachers dominating in number), gender balance did not form part of my selection criteria. The participants were from 26 to 47 years of age and their first language was Sesotho. Their qualifications ranged from a diploma to a bachelor's degree in education. Of the four support teachers, three had a qualification or training in braille. Data was collected using two focus group discussions: one was comprised of four support teachers (three females and one male) and the other four regular teachers (all female). My prompts during the discussions helped to keep their focus on the research topic, thus, in line with Burton and Bartlett (2005), increasing the trustworthiness of the results. Thus, data emerged as the participants discussed the research topic among themselves. According to Denscombe (2007), this approach also enables participants to learn from each other. The discussion venues were classrooms chosen by each group. The discussions were audio recorded. Sesotho was spoken mostly during the discussions, so the data was first transcribed verbatim, and then translated into English. The translated versions of the data were given to the participants for corrections and approval. The data was then analysed thematically following Maree (2007). Research ethics were adhered to prior to and during data collection. For example, permission was sought from the Maseru District Education Office to conduct the research and from the principal of the school. Informed consent was also granted by the participants. Confidentiality was maintained in reporting the findings. However, the anonymity of the school could not be guaranteed since it has been indicated that there is just one secondary school in Lesotho that offers braille services to learners with VI.

\section{Results}

Prior to presenting and discussing the results of this study, there is a limitation that must be considered since it will have an effect on how the results are understood. It is necessary to mention that among the support teachers, none could be described as having extensive training on teaching learners with VI.

This study focused on investigating the views of teachers about the inclusion of learners with VI in their mainstream school. Data analysis presented four categories: teachers' opinions about educational placement for children with VI; teaching strategies; benefits of including children with VI in a regular school; and challenges facing the integration of children with VI into mainstream secondary schools. In the excerpts, the following acronyms are used to ensure teacher anonymity:

- RT: Regular teacher 
- ST: Support teacher

\section{Teachers' opinions about educational placement for children with VI}

The teachers believed that a regular school is the best placement for children with VI. They discredited the idea of teaching children with VI in special schools since they regarded this as a form of discrimination against such learners. They also thought that special schools promote the isolation of children with VI from their sighted community. It was argued that doing this could deprive them of important social interactions with sighted peers. The idea of special schooling for children with VI was also criticised as giving the wrong impression that children with VI are unique and should therefore not mix with their peers. According to the teachers, this isolation is unnecessary since children with VI have sighted family and community members with whom they live, without any problem, at home. This is how some of these ideas were presented.

In my opinion, children with visual impairment should not be taken to special schools. They must be taken to regular schools where they will learn alongside others. (RT)

Even in their families and churches there are those with and without disabilities, so I do not understand why they should be excluded from mainstream schooling. (RT)

However, where regular schools were poorly equipped to meet the needs of children with VI, they preferred special schools.

To a certain extent, I think special schools are good for them because that's where they will find proper services and facilities that will make it easier for them to learn. (RT)

\section{Teaching strategies}

The teachers discussed several teaching methods and strategies they found helpful in their teaching of mixed-ability classes (including some learners with VI). To them, the learnercentred teaching methods that were mostly helpful were discussion and presentation.

According to them, other teaching methods such as drama, role play, video presentations, discovery, and experimentation could be time consuming while some of them required resources that they did not have. They stated that depending on the topic being taught, they bring to class teaching aid materials that will engage all learners, including those with VI. For learners with VI, the teaching aid material often targeted their senses of touch, hearing, and taste (where appropriate). They commented that verbal teaching was very useful to them since it could reach both learners with VI and those without.

The teachers stated that they allowed learners with VI to take their learning equipment to classes with them. The equipment, inter alia, often included Perkins (brailing machines) and brailed texts. For learners who required enlarged printing, the teachers wrote for them on large chart paper, using writing that was suitable for them. With learners who used braille, the teachers stated that they used to give them brailed text a day before teaching about the 
contents of that text. This strategy offered the learners with VI ample time to read because braille reading was perceived to be very slow.

The support teachers reported that they often brailed text for learners with VI, where none existed. They also used a tracing wheel to make simple diagrams readable for learners with VI. These teachers stated that they seated learners with low vision closer to the writing board, so that they could have a better chance of seeing the writing on it.

The teachers also identified some of the benefits of including children with VI in their mainstream schools. As maintained by the teachers, some of these benefits were reaped by the learners (with and without VI), and others by the teachers themselves.

\section{Benefits of including children with VI in a regular school}

It was contested by the teachers that mainstream schooling enabled children with and without VI to learn to live harmoniously together, thereby providing a platform for building inclusive communities. It was also maintained that an inclusionary approach could have equipped children with VI with strategies to deal with life challenges, in the same way as it did for other children. The teachers argued that academically good learners (fast-learners), with or without VI, helped slow-learners with school work. Moreover, in relation to learners without VI, they assisted those with VI to move within their school campus, and, where there was a shortage of brailed textbooks, they read their normally printed textbooks for them. One teacher argued,

Through inclusion, children with VI learn to live with different types of people that are found within their communities. While in inclusive schools, those with VI grow the same way as others. In my school, the sighted children assist those with VI to navigate our school campus. They also read their textbooks for them when there are no brailed ones for those with VI. (ST)

The teachers stated that the uniqueness of their school (as mentioned above, the only secondary school in Lesotho that offers braille and other services to learners with VI) has helped them to negotiate with the MOET and donor agencies, like non-governmental organisations (NGOs) for assistance with equipment and other necessities. They stated that inclusion of children with VI in their school had improved their attitudes towards learners with disabilities.

We have learned to have patience and tolerance with learners who learn in ways that are unusual, such as those who use braille. (ST)

The teachers stated happily that they enjoyed teaching mixed ability classes to the point that they were proud to have chosen a teaching career. They showed that inclusion had equipped them with skills to handle any challenge related to teaching. Moreover, it had taken them out of their comfort zone, which had made teaching even more interesting for them. The regular teachers mentioned that they were joyful to see some of their learners with VI succeed in life. They also stipulated that their classroom interaction with learners with VI had familiarised 
them with braille. This had helped them to mark brailed answers in class, which enabled them to give immediate feedback about learning progress for learners with VI.

\section{Challenges}

The challenges that emanated from the group discussions included infrastructural barriers, insufficient human and material resources and skills, and a rigid, centralised curriculum. The teachers affirmed that the physical environment of their school was unsuitable for learners with VI. They stated there were certain places in their school campus that were inaccessible to learners with VI. They lamented that in such places learners with VI could easily bump into trees or fall into deep furrows that were uncovered. The teachers disapproved of the random tree planting in their school campus since this was perceived to make the movement of learners with VI unsafe. They also complained about steep stairs at some places and in some buildings, saying that these hampered the smooth movement of learners with VI.

However, the support teachers stated they were overloaded with work. It transpired that in addition to their classroom support services, they also had subjects to teach. They stated that despite being only eight in number, it was also their responsibility to braille the teaching materials for all the subjects offered in their school. They objected that this had put pressure on them. One of them said,

As support teachers, we are overloaded with work. I am given subjects to teach and I also have to work as a support teacher in some subjects. I braille teaching materials for my own subjects as well as for others for which I provide support. This is too much work for me. (ST)

Both groups stated that children with VI often have additional needs that call for other specialists. So, they believed that if they could be afforded such support, it would make their work manageable. Material resources also appeared to be a big challenge in the school. The teachers noted the scarcity of drawing and braille equipment. They stated that under normal circumstances each learner with VI was supposed to have a Perkins for brailing, but that this was not the case in their school. The embossers (faster braille machines than the Perkins) which the support teachers used when preparing examination question papers for learners with VI, were said to number only two. This increased pressure on the support teachers during the examination period, forcing them to work extra hours.

Furthermore, the teachers expressed their concerns over the failure of their curriculum to allow for inclusive teaching strategies. They said that the syllabus content was too much for slow-learners and those with VI. They affirmed that learners with VI often required a slower teaching pace since braille reading was comparatively slower. Additionally, the teachers asserted that because there was too much syllabus content and a limited time to cover it, learners with VI were often left behind when teaching was done at a faster pace in order to satisfy examination requirements. 
In Lesotho, the terminal examination question papers are prepared by the Examinations' Council of Lesotho (ECOL). The teachers believed that the brailed question papers from ECOL were ambiguous in terms of diagrams, which their learners with VI could not read. They said that they had, on a number of occasions, unsuccessfully pleaded with ECOL to refrain from what they saw as malpractices. The teachers repeatedly emphasised that their curriculum did not meet the educational needs of learners with VI.

The other challenges that the teachers raised involved the accidents that learners with VI got involved with while going for eye check-ups outside the school. They appealed to optometrists to travel to their school in order to carry out such check-ups. They also expressed concern over their government's late school fees' payment, which resulted in sponsored learners been sent home to collect the fee. The teachers stated that late payment of school fees made it difficult for their school to purchase essential substances such as food and teaching-aid materials. When sent home, these learners lose out academically, they claimed.

It appeared that while typing in class during the lessons, the Perkins made a lot of noise that disturbed other learners, and the teachers affirmed that they had no strategies to ameliorate this problem. On the same note, the embossers appeared to pose a health hazard to the support teachers. The support teachers insisted that these machines made many spelling errors, which often called for thorough editing that, in turn, strained their eyes. "When printing, the machine makes too much noise [and] that also strains our ears," they asserted.

\section{Discussion}

As explained above, this study investigated the opinions and views of the teachers about educational placement for learners with VI. It also examined their experiences in relation to the teaching of mixed-ability learners, some of whom are visually impaired. The results revealed that the teachers have mixed opinions about the integration of children with VI into mainstream schools. Their supportive views towards the inclusion of learners with VI into mainstream schools seemed to stem partly from what they saw as their natural instincts of caring for all children regardless of their disabilities. Culturally, Basotho believe in bringing up children as a unit, in order to prevent one child from missing out on cultural values and norms as Lesitsi (1990) has reminded us. Thus, if isolated from others, a child would lose out in respect of the moral aspects of life. Moreover, the fact that female teachers dominated in numbers could have served as a benchmark for the inclusion of children with VI. Within Basotho societies, women are mostly entrusted with child care and nurturing.

The teachers' positive views about the inclusion of children with VI appeared also to be influenced by the positive aspects they had witnessed from this arrangement. They appeared to value the positive interactions between learners with VI and their peers. They stated that IE has enabled the two groups to learn to live with each other and has equipped those with VI with skills to cope with daily challenges. They were also very proud of their former students with VI who had gone on to very good careers because of the quality education they were offered at this school. Furthermore, they stated that the inclusion of children with VI in their 
school has made them enjoy teaching by expanding their teaching skills. Indeed, past research (see, for example, Emam and Mohamed, 2011) shows that teachers' positive attitudes toward IE impacts positively on its implementation in schools.

Nonetheless, the teachers seemed not to promote reciprocal assistance between learners with VI and their peers. Drawing from their discussions, those with VI seemed to be mostly the recipients of help from their peers. This situation is highly discouraged. Lamichhane (2017) has stated that the over-reliance by learners with VI on their peers to help them with school work could affect their friendships, resulting in those with VI feeling isolated. It could also affect the confidence of those with VI to do things on their own.

The teachers seemed to be very concerned about the lack of resources in their school, which made it difficult to teach learners with VI effectively. Consequently, they felt that children with VI could benefit more in special schools, which they believed could be optimally resourced. Nonetheless, the teachers concluded that mainstream schools should be properly equipped so that they can accommodate all types of learners.

The teachers revealed several teaching strategies they believed helped them to teach their diverse learners. Learner-centred approaches to teaching were at the core of their classroom pedagogy. Strategies that they employed more were learner discussions and class presentations. Indeed, learner-centred teaching approaches are considered to be the core of IE (Figueiras \& Arcavi, 2014). Nonetheless, over-reliance on discussions and presentations does not constitute good teaching. They complained about their curriculum requiring them to cover too much content in a short time in order to prepare learners for examinations. They thought that other teaching methods would be time consuming while others would require equipment they did not have. Clearly, the latter necessitates equipping teachers with more improvisation strategies while the former could imply a lack of practical knowledge of other teaching methods. Perhaps the teachers were more comfortable with these two teaching methods that helped them to cover a lot of content in a short space of time. But, their faster pace of teaching probably left behind many students with VI and, hence, their over-reliance on peers.

The teachers discovered that braille reading takes longer, so they adopted a strategy of allowing learners with VI to read ahead of others without this need. A similar strategy appeared to work well for Malawian teachers of children with albinism (Lynch et al., 2014). The support teachers traced simpler diagrams with a drawing wheel, so that learners with VI could have access to them. The support teachers also brailed teaching materials where none existed, but they complained about having too much work.

The classroom seating arrangement appeared to be paramount to the teachers. The learners with low, but usable vision, were seated closer to the writing board so that they could see the writing on the board easily. Indeed, this is highly encouraged for teaching learners with low vision (Mastropieri \& Scruggs, 2010). Although the Perkins produced a lot of noise that disturbed other learners, the teachers allowed their use for the purpose of enabling learners with VI to write in class. Indeed, Lamport, Graves, and Ward (2012) have expressed their 
belief that classroom management is essential to enable curriculum accessibility, especially for learners with VI.

Interestingly, the teachers seemed uninformed about the Individualised Education Plan (IEP). IEP is a written plan that describes the education programme and services required by an individual learner. It is based on a detailed assessment of the learner's strengths and needs (Ontario Ministry of Education, 2004). Considering the importance of IEPs in IE, it is important that this area be improved.

The teachers highlighted a number of challenges that hamper progress in their school. Scholars have argued that "[in] order to provide a truly inclusive school the physical environment needs to be safe and accessible to all students" (Winter \& O'Raw, 2010, p. 56). However, the teachers described the physical environment of their school as being potentially dangerous to learners with VI because of random tree planting, steep stairs, and deep uncovered furrows. The teachers also mentioned concerns about shortages of teaching and learning equipment such as Perkins, embossers, and drawing materials. Shortage of resources was exacerbated by the government of Lesotho's late payment of school fees, the teachers argued. The late payment also affected learners academically since they were often sent home to collect the fees. In their Tanzanian study, Westbrook and Croft (2015) concluded that resource challenges to successfully implementing IE overrode other challenges.

Finally, the brailing machines also led to some challenges. The teachers reported that the embossers made a very loud noise when printing, and the Perkins also produced a lot of noise when learners were typing in class; this disturbed other learners frequently.

\section{Recommendations and conclusion}

Although the teachers were not very much in favour of special schooling, and were proud of their work in relation to teaching classes that have some learners with VI, inadequate resources (particularly for learners with VI) prompted them to doubt whether there could be integration of children with VI into mainstream schools. In Lesotho, the MOET is the major stakeholder in secondary education. However, several studies in Lesotho (see Eriamiatoe, 2013; Mosia, 2014; Ralejoe, 2016) have shown that the government of Lesotho has no interest in making IE work. "These few facilities [for implementing IE in Lesotho schools] are usually made available at the insistence of disabled people's organisations" (Eriamiatoe, 2013 , p. 2). Thus, a shortage of funds was not a major impediment for resourcing inclusive schools in Lesotho, but MOET's lack of interest in IE is. It is argued by Winter and O'Raw (2010), on the one hand, that countries that have a capitalist view of education do not see IE as a good investment. Could this be MOET's view on education? On the other, this implies a conflict of interest since Lesotho is a signatory to the CRPD that advocates for IE. Therefore, it is recommended that Lesotho considers it a priority to fulfil its obligations to IE as mandated by the CRPD. MOET should collaborate with NGOs and various professionals (such as psychologists and IE specialists) to support (inclusive) schools for the purpose of making IE work. Indeed, the teachers recommended that professionals from other fields be 
made available to them so that they could assist with equipment, counselling, motivation, and eye-testing where necessary.

There is consensus among scholars that examination-oriented curricula compromise inclusion initiatives. Thus, it is vital that the current curriculum be revamped in order to give teachers the autonomy to adapt it to individual learner needs. The question papers prepared by ECOL for learners with VI were also considered to be ambiguous in terms of complex diagrams and, this way, failed the learners. Since it is the responsibility of education authorities to provide conducive learning conditions for all learners (UNESCO, 1994), it is recommended that ECOL collaborates with teachers of learners with VI in order to prepare question papers that can accommodate such learners.

The teachers were concerned about the physical environment in their school not being safe for learners with VI. Consequently, they appealed to their authorities to ensure that their school ground was paved, steep stairs replaced with ramps, and the trees planted in an orderly way so that the environment is safe for all learners. The support teachers complained about work overload and demanded that more support teachers be hired in order to decrease their workload. It was also desired by both groups of teachers that the regular teachers be equipped with more special education skills in order to make inclusion in their school prosper.

The brailing machines were also considered to create some challenges. The teachers reported that the embossers made a very loud noise when printing, and the Perkins also produced a lot of noise when learners were typing in class, which often disturbed other learners. While there appeared to be no immediate solution to the problems caused by Perkins, the teachers should be provided with ear protection equipment when using the embossers.

In brief, it can be concluded that cultural influences had a big impact on the teachers' passion to teach mixed ability classes despite the challenges they encountered; they believed that it was their responsibility to teach all children without discriminating against those with VI. When they are teaching a class that includes learners with VI, teachers should consider the following:

(a) Encourage teamwork among learners involving grouping learners so that they can work together in small learning groups. In these groups, learners with VI should be paired with those without VI.

(b) Use the oral teaching method because learners with VI rely more on their hearing.

(c) Ensure audibility, with clear instruction and provision of information. Avoid making vague statements.

(d) Adapt writing assessment methods and use assistive technology. Learners with VI must be allowed and encouraged to use audio tapes, brailing machines, and magnifiers in order to maximise their participation in the classroom.

(e) Allow children with low vision to move closer to the chalkboard.

(f) Provide large-print versions of textbooks and examination scripts.

(g) Allocate additional time for those with VI to complete school and national examinations (see Lynch, Lund, \& Massah, 2014; Mastropieri \& Scruggs, 2010). 
Further research on the views of other stakeholders (like the learners, for example) is recommended. Research on the MOET officials' understanding and views about IE is also recommended in order to establish exactly how they perceive IE (particularly regarding learners with VI) and what they do to promote it in Lesotho's schools.

\section{References}

Belay, T. E. (2005, November). African perspective on visual impairments ICTs and policies: A personal experience, a variety of perspectives and technological solution. Paper presented at UNESCO World Summit on the Information Society Workshop on ICT and Persons with Disabilities. Tunis, TN.

Booth, T., \& Ainscow, M. (2000). The Index for Inclusion. London, UK: CSIE Bristol.

Burton, D., \& Bartlett, S. (2005). Practitioner research for teachers. London, UK: SAGE.

Dakwa, F. E. (2014). Inclusion of children with visual impairments in regular schools: A Zimbabwean perspective. International Journal of Academic Research in Progressive Education and Development, 3(1), 89-97. https://doi=10.1.1.678.644\&rep=rep1\&type=pdf

Denscombe, M. (2007). The good research guide for small-scale research projects. Berkshire, UK: Open University Press.

Emam, M. M., \& Mohamed H. H. A. (2011). Pre-school and primary school teachers' attitudes towards inclusive education in Egypt: The role of experience and selfefficacy. Social and Behavioural Sciences, 29, 976-985. https://doi.org/10.1016/j.sbspro.2011.11.33

Eriamiatoe, P. (2013). Realising Inclusive Education for Children with Disabilities in Lesotho. Pretoria, RSA: University of Pretoria.

Figueiras, L., \& Arcavi, A. (2014). A touch of mathematics: Coming to our senses by observing the visually impaired. ZDM: The International Journal on Mathematics Education, 46, 123-133. http://dx.doi.org/10.1007\%2Fs11858-013-0555-x

Government of Lesotho, Ministry of Health and Social Welfare National Disability and Rehabilitation Policy (NDRP). (2011). Retrieved from http://www.gov.ls/social

Hay, J. F., Smit, J., \& Paulsen, M. (2001). Teacher preparedness for inclusive education. South African Journal of Education, 21(4), 213-218. https://www.researchgate.net/publication/228793568

International Classification of Diseases (ICD)-10 (2016). Diseases of the eye and adnexa (H00-h59, chap. VII). Geneva, CHE: World Health Organization. 
Khatleli, P., Mariga, L., Phachaka, L., \& Stubbs, S. (1995). Schools for all: National planning in Lesotho. In B. O’Toole \& R. McConkey (Eds.), Innovations in developing countries for people with disabilities (pp. 135-160). Chorley, UK: Lisieux Hall.

Lamichhane, K. (2017). Teaching students with visual impairments in an inclusive educational setting: A case from Nepal. International Journal of Inclusive Education, 21(1), 1-13. Retrieved from https://doi.org/10.1080/13603116.2016.1184323

Lamport, M. A., Graves, L., \& Ward, A. (2012). Special needs students in inclusive classrooms: The impact of social interaction on educational outcomes for learners with emotional and behavioural disabilities. European Journal of Business and Social Sciences, 1(5), 54-69. Retrieved from http://www.ejbss.com/recent.aspx

Lesitsi, A. M. (1990). Seemahale. Randburg, RSA: Hodder \& Stoughton Educational.

Lynch, P., Lund, P., \& Massah, B. (in press). Identifying strategies to enhance the educational inclusion of visually impaired children with albinism in Malawi. International Journal of Educational Development. Retrieved from https://research.birmingham.ac.uk/portal/files/18618153/ViewPageProof_EDEV_158 0.pdf

Maree, K. (2007). First steps in research. Pretoria, RSA: van Schaik.

Mastropieri, M. A., \& Scruggs, T. E. (2010). The inclusive classroom: Strategies for effective differentiated instruction. New Jersey, NY: Upper Saddle River.

McLean, M. A. (2008). Teaching about disability: An ethical responsibility? International Journal of Inclusive Education, 12, 605-619. Retrieved from https://doi.org/10.1080/13603110802377649

Mosia, A. P. (2014). Threats to inclusive education in Lesotho: An overview of policy and implementation challenges. Routledge, UK: Taylor \& Francis.

Mukhopadhyay, S. (2013). Voices of experience: Botswana primary school teachers on inclusive education. European Journal of Educational Studies, 5(1), 73-85.

Ontario Ministry of Education. (2004). The individual education plan (IEP): A resource guide. Toronto, Canada: Queen's Printer for Ontario.

Ralejoe, M. C. (2016). The perceptions of Lesotho secondary schools' teachers about the inclusion of students with disabilities (Unpublished doctoral dissertation). University of South Africa, Pretoria, RSA.

Sharma, S. (2013). Qualitative approaches in mathematics education research: Challenges and possible solutions. Education Journal, 2(2), 50-57.

doi:10.11648/j.edu.20130202.14 
UNESCO. (1994). The Salamanca Statement and Framework for Action on Special Needs Education. Paris, FR: UNESCO.

United Nations Convention on the Right of Persons with Disabilities (CRPD). (2006). Retrieved from http://www.un.org/disabilities/convention/conventionfull.shtml.

Westbrook, J., \& Croft, A. (2015). Beginning to teach inclusively: An analysis of newly qualified teacher pedagogy in lower primary classes in Tanzania. Teaching and Teacher Education, 51, 38-46. Retrieved from http://dx.doi.org/10.1016/j.tate.2015.05.003

Winter, E., \& O'Raw, P. (2010). Literature review of the principles and practices relating to inclusive education for children with special educational needs. National Council for Special Education (NCSE). Retrieved from http://www.ncse.ie

Yahalom, C., Tzur, V., Blumenfeld, A., Greifner, G., Dalia, E., Rosenmann, A., Glanzer, S., \& Anteby, I. (2012). Refractive profile in oculocutaneous albinism and its correlation with final visual outcome. British Journal of Ophthalmology, 96(4), 537-539. doi:10.1136/bjophthalmol-2011-300072

Zulch, T. M. (2010). Including learners with visual impairments in a Namibian mainstream secondary school (Unpublished doctoral dissertation). Stellenbosch University, Stellenbosch, RSA. 